\title{
Mental Health Implications of COVID-19 in Kenya
}

Ochillo Marylyn A. ${ }^{1}$, Elsie Ivy O. ${ }^{2}$

Author Info:

'Impact Research and

Development Organization,

Kisumu, Kenya;

${ }^{2}$ School of Medicine, University of Nairobi, Nairobi, Kenya

\section{Corresponding Author:}

Marylyn A. Ochillo

Impact Research and

Development Organization

P.O BOX 9171-40141-Kisumu, Kenya

Email/Contact:

marilynochillo@yahoo.com

+254797679338

\section{Dear Editor,}

As the COVID-19 pandemic continues to spread rapidly worldwide, it is certainly having an immense effect on the mental wellbeing on people thereby increasing the number of people with elevated levels of stress, depression or anxiety.1 Developing countries will undoubtedly have serious mental health implications due to the poor or almost non-existent mental health services.

In Kenya, mental health is still somewhat neglected mainly because only $0.05 \%$ of the Governments' health budget allocation goes to mental health.2 The allocated health budget largely focuses on communicable diseases despite the impact of mental health on the Kenyan population. Although there are no accurate data on the prevalence of mental disorders in Kenya, various studies have shown that the prevalence of depression generally varies from $19 \%$ in household review studies 2 to $42 \%$ among the general population visiting the health facilities.3 Similar to other African countries, Kenya has a shortage of mental health professionals. Mathari hospital is the country's only mental referral facility where one nurse handles up to 150 patients. 4 In a country with only approximately 100 psychiatrists serving a population of 45 million, only a third of the psychiatrists work in the government health facilities.5 The rest of the psychiatrists work in the private health facilities that are generally more expensive making them inaccessible to the majority of the population due to the unaffordable consultation fees.

Keywords: COVID-19, Pandemic, Coronavirus, Mental Health Implication

\begin{tabular}{|c|c|c|}
\hline QR Code & \multicolumn{2}{|l|}{ Article Info } \\
\hline \multirow{2}{*}{$\begin{array}{l}\text { Scan Me for } \\
\text { Full Text }\end{array}$} & Received: 11 June 2020; & Published Online: 4 July 2020 \\
\hline & \multicolumn{2}{|l|}{ How to cite this article in Vancouver Style? } \\
\hline \multirow{3}{*}{ 口ifing } & \multicolumn{2}{|c|}{$\begin{array}{l}\text { Ochillo M, Elsie I. Mental Health Implications of COVID-19 in Kenya. Europasian J Med Sci [Internet]. 2020Jul.4 [cited } \\
\text { 2020Jul.4];2(2):36-8. Europasian J Med Sci. 2020; 2(Covid-19 Special Issue):135-137. https://doi.org/10.46405/ejms. } \\
\underline{\text { v2i2.111 }}\end{array}$} \\
\hline & \multicolumn{2}{|l|}{ Disclaimer } \\
\hline & Conflict of Interest: None Declared; & e of Support: Nil \\
\hline L) View PDF & \multicolumn{2}{|c|}{$\begin{array}{l}\text { Copyright: } \odot 2020 \text { by author(s). This is an open access article distributed under the terms of the Creative } \\
\text { Commons Attribution International License } 4.0 \text { (http://creativecommons.org/licenses/by/4.0/) which permits } \\
\text { unrestricted use, distribution, and reproduction in any medium, provided the original work is properly cited. }\end{array}$} \\
\hline & \multicolumn{2}{|c|}{ Publisher's Note } \\
\hline & Irnal of Medical Sciences (EJMS) (www.europasianjournals.org) is an c & \\
\hline
\end{tabular}


As the COVID-19 pandemic continues to spread rapidly worldwide, it is certainly having an immense effect on the mental wellbeing on people thereby increasing the number of people with elevated levels of stress, depression or anxiety. 1 Developing countries will undoubtedly have serious mental health implications due to the poor or almost nonexistent mental health services.

In Kenya, mental health is still somewhat neglected mainly because only $0.05 \%$ of the Governments' health budget allocation goes to mental health. 2 The allocated health budget largely focuses on communicable diseases despite the impact of mental health on the Kenyan population. Although there are no accurate data on the prevalence of mental disorders in Kenya, various studies have shown that the prevalence of depression generally varies from $19 \%$ in household review studies 2 to $42 \%$ among the general population visiting the health facilities.3 Similar to other African countries, Kenya has a shortage of mental health professionals. Mathari hospital is the country's only mental referral facility where one nurse handles up to 150 patients. 4 In a country with only approximately 100 psychiatrists serving a population of 45 million, only a third of the psychiatrists work in the government health facilities. 5 The rest of the psychiatrists work in the private health facilities that are generally more expensive making them inaccessible to the majority of the population due to the unaffordable consultation fees.

Kenya reported the first positive case of COVID-19 on 13th, March 2020 in a 27-year-old Kenyan woman who had travelled from the United States via London, United Kingdom. As at 22 June 2020, Kenya had reported a total of 4, 738 confirmed cases of COVID-19, and 123 deaths. 6 With the world having introduced physical distancing and lock down measures to cope with COVID-19 that has since spread to over 187 countries globally, Kenya was not been left behind. The Kenyan Government imposed a national curfew running between $7 \mathrm{pm}$ and $5 \mathrm{am}$ daily on 27th March 2020 with movements into and out of four counties (Nairobi, Mombasa, Kwale and Kilifi) that are considered hotspots in the country restricted except for essential services. The major effects of COVID-19 reported in the Kenyan mainstream media is a spike in gender-based violence, loss of jobs, and household food insecurity. Increase in the number of mental health issues has however been left out by the press yet it is undeniable that the fear of the uncertain future and stigma of COVID-19 is fueling the mental health crisis in Kenya. Kenya is therefore looking at a second pandemic of mental health problems related to COVID-19. Although measures such as lockdowns and physical distancing are meant to slow down the transmission of COVID-19, such measures are likely to contribute to the rise in mental health illness. Outbreaks of infectious diseases have often been associated with depression and stigma.7 Furthermore, the effects of COVID-19 such as loss of employment can worsen the mental health of the population1 and such effects are more likely to remain long after the COVID-19 pandemic has been done with, hence an urgent need to put in place measures to handle the mental health needs of the general population in Kenya.

The good news is that Kenya has taken the first step by launching the mental health policy in 2016. The policy provides for the integration of mental health services with other health services. However, the policy is yet to be fully adopted and the funding allocation to mental health is still very low. Moreover, Kenya has devolved the health services to its 47 counties where at the national level, the Ministry of Health only gives technical advice and overall guidance on the county policies. Each county then prioritizes their health services according to their own health needs and context which usually leads to poor planning and delivery of mental health services that are trickled down to the county residents.

With the already poor health system in Kenya and the lack of enough mental health clinicians, COVID-19 therefore pushes mental health to the lowest order of spectrum. Supporting mental health and wellbeing is important at all times and when life becomes difficult due pandemics such as the COVID-19, it is vital for health systems to support in looking at the mental health of the population. There is an urgent need to prioritize mental health issues and services in Kenya to enable better handle mental health issues associated with the future pandemics.

\section{REFERENCES}

1. World Health Organization (WHO). Mental Health and COVID-19. 2020. [Accessed 13th June 2020]. [Link]

2. Mutiso VN, Musyimi CW, Tomita A, Loeffen L, Burns JK, Ndetei DM. Epidemiological patterns of mental disorders and stigma in a community household survey in urban slum and rural settings in Kenya. Int J Soc Psychiatry. 2018;64(2):120-129. https:// 


\section{doi:10.1177/0020764017748180}

3. Ndetei DM, Khasakhala LI, Kuria MW, Mutiso VN, Ongecha-Owuor FA, Kokonya DA. The prevalence of mental disorders in adults in different level general medical facilities in Kenya: a cross-sectional study. Ann Gen Psychiatry. 2009;8:1. Published 2009 Jan 14. https://doi:10.1186/1744-859X-8-1

4. Jenkins R, Kiima D, Njenga F, Okonji M, Kingora J, Kathuku $D$, et al. Integration of mental health into primarycarein Kenya.World Psychiatry.2010;9(2):118120. https://doi:10.1002/j.2051-5545.2010.tb00289.x
5. World Health Organization (WHO). WHO's mental health Atlas. J Nutr Educ. 2014. [Accessed 13th June 2020]. [Link]

6. World Health Organization (WHO). Coronavirus Disease 2019 (COVID-19) Situation Report - 154.; 2020. [Accessed 9th June 2020]. [Link]

7. Bao Y, Sun Y, Meng S, Shi J, Lu L. 2019-nCoV epidemic: address mental health care to empower society. Lancet. 2020;395(10224):e37-e38.https:// doi:10.1016/S0140-6736(20)30309-3 